\title{
Predictors of Risk and Success of Obesity Surgery
}

\author{
Felix Nickel $^{\mathrm{a}} \quad$ Javier R. de la Garza ${ }^{\mathrm{a}}$ Fabian S. Werthmann ${ }^{\mathrm{a}}$ \\ Laura Benner $^{b}$ Christian Tapking ${ }^{a}$ Emir Karadza ${ }^{a}$ \\ Anna-Laura Wekerle ${ }^{a}$ Adrian T. Billeter ${ }^{a}$ Hannes G. Kenngott ${ }^{a}$ \\ Lars Fischer $^{a}$ Beat Peter Müller-Stich ${ }^{a}$ \\ aDepartment of General, Visceral and Transplantation Surgery, University of Heidelberg, \\ Heidelberg, Germany; ${ }^{b}$ Institute of Medical Biometry and Informatics, University of \\ Heidelberg, Heidelberg, Germany
}

\author{
Keywords \\ Excess weight loss · Comorbidities · Years of obesity · Age of onset of obesity · Risk of \\ complications
}

\begin{abstract}
Background: Obesity surgery has proven successful for weight loss and the resolution of comorbidities. There is, however, little evidence on its success and the risk of complications when considering age of onset of obesity (AOO), years of obesity (YOO), preoperative body mass index (BMI), Edmonton obesity staging system (EOSS) score, and age as possible predictors of weight loss, the resolution of comorbidities, and the risk of complications. Methods: Patients who underwent Roux-en-Y gastric bypass (RYGB) and laparoscopic sleeve gastrectomy (LSG) from a prospective database were analyzed. Multiple regression analyses were used to predict comorbidities and their resolution, percentage excess weight loss (\%EWL) and total weight loss (\%TWL) 12 months after surgery, and the risk of complications using the predictors AOO, YOO, age, EOSS, and BMI. Results: 180 patients aged $46.8 \pm 11.1$ years with a preoperative BMI $49.5 \pm 7.5$ were included. The number of preoperative comorbidities was higher with older age $(\beta=0.054 ; p=0.023)$ and a greater $\mathrm{BMI}(\beta=0.040 ; p=0.036)$ but was not related to $\mathrm{AOO}$ and YOO. Patients with $\mathrm{AOO}$ as a child or adolescent were more likely to have an EOSS score of $\geq 2$. Greater preoperative BMI was negatively associated with \%EWL $(\beta=-1.236 ; p<0.001)$ and older age was negatively associated with \%TWL $(\beta=-0.344 ; p=0.020)$. Postoperative compli-
\end{abstract}

Felix Nickel and Javier R. de la Garza contributed equally to this work. 
Nickel et al.: Predictors of Risk and Success of Obesity Surgery

cations were positively associated with EOSS score (odds ratio [OR] 1.147; $p=0.042$ ) and BMI (OR 1.010; $p=0.020$ ), but not with age. AOO and YOO were not related to postoperative outcome. Conclusion: Greater BMI was associated with a lower \%EWL and age was associated with a low \%TWL. YOO and AOO did not influence outcome. Age, BMI, and EOSS score were the most important predictors for risk and success after obesity surgery. Surgery should be performed early enough for optimal outcomes.

(C) 2019 The Author(s)

Published by S. Karger AG, Basel

\section{Introduction}

Obesity is a worldwide epidemic disease [1] and a major risk for comorbidities such as diabetes mellitus type 2 (DM2), arterial hypertension, stroke, coronary heart disease, pulmonary disease, and $>5$ different cancers [2]. Treatment of obesity is a major concern for physicians [3]. The age of onset of obesity (AOO) varies greatly, and can occur in childhood, adolescence, or adulthood. Childhood obesity continues to be a major focus in public health [4]. Obese children may be at risk for short-term health consequences [5] and long-term tracking of obesity to adulthood [6]. Excess weight gain during adolescence often persists into adult life and is compounded during child-bearing years. Adolescence is a "high-risk period" for weight gain, characterized by critical changes in body composition, insulin sensitivity, eating and activity behaviors, and psychological adjustments [7].

Presently, obesity surgery is the only available treatment for morbid obesity that consistently achieves and maintains substantial weight loss and improves obesity-related comorbidity and quality of life [8-12]. Laparoscopic Roux-en-Y gastric bypass (RYGB) and laparoscopic sleeve gastrectomy (LSG) have been the most commonly performed obesity procedures in the last decade. The risk of complications is acceptable in most patients, but there can be considerable morbidity and even mortality $[13,14]$. However, there is insufficient evidence on the risk factors for perioperative complications as opposed to the optimal timing of surgery. The aim of the Edmonton obesity staging system (EOSS) is to classify patients according to their current obesity-related complications [15]. Although the majority of patients achieve a successful degree of weight loss after surgery, typically defined as $>50 \%$ excess weight loss (\%EWL), there is an important minority of patients $(15-20 \%)$ that fail to achieve this goal [16]. Failure to achieve successful weight loss after surgery is likely multifactorial, involving provider-level (e.g., technical factors and preoperative patient education) and patient-level characteristics [17-19].

Currently, there is limited evidence on the influence of AOO and the duration of obesity on the risks and success of obesity surgery. By knowing patients' A00, one can determine their years of obesity (YOO).

The aim of this study was to evaluate the role of $\mathrm{AOO}$ and YOO, together with other possible predictors such as age, body mass index (BMI), gender, and EOSS score, in the success of obesity surgery in terms of weight loss, the resolution of comorbidities, and the risk of complications.

\section{Materials and Methods}

A retrospective analysis of a prospectively collected database from the Department of General, Visceral and Transplant Surgery of the Heidelberg University Hospital was conducted. We included all patients who underwent RYGB or LSG between January 2006 and November 


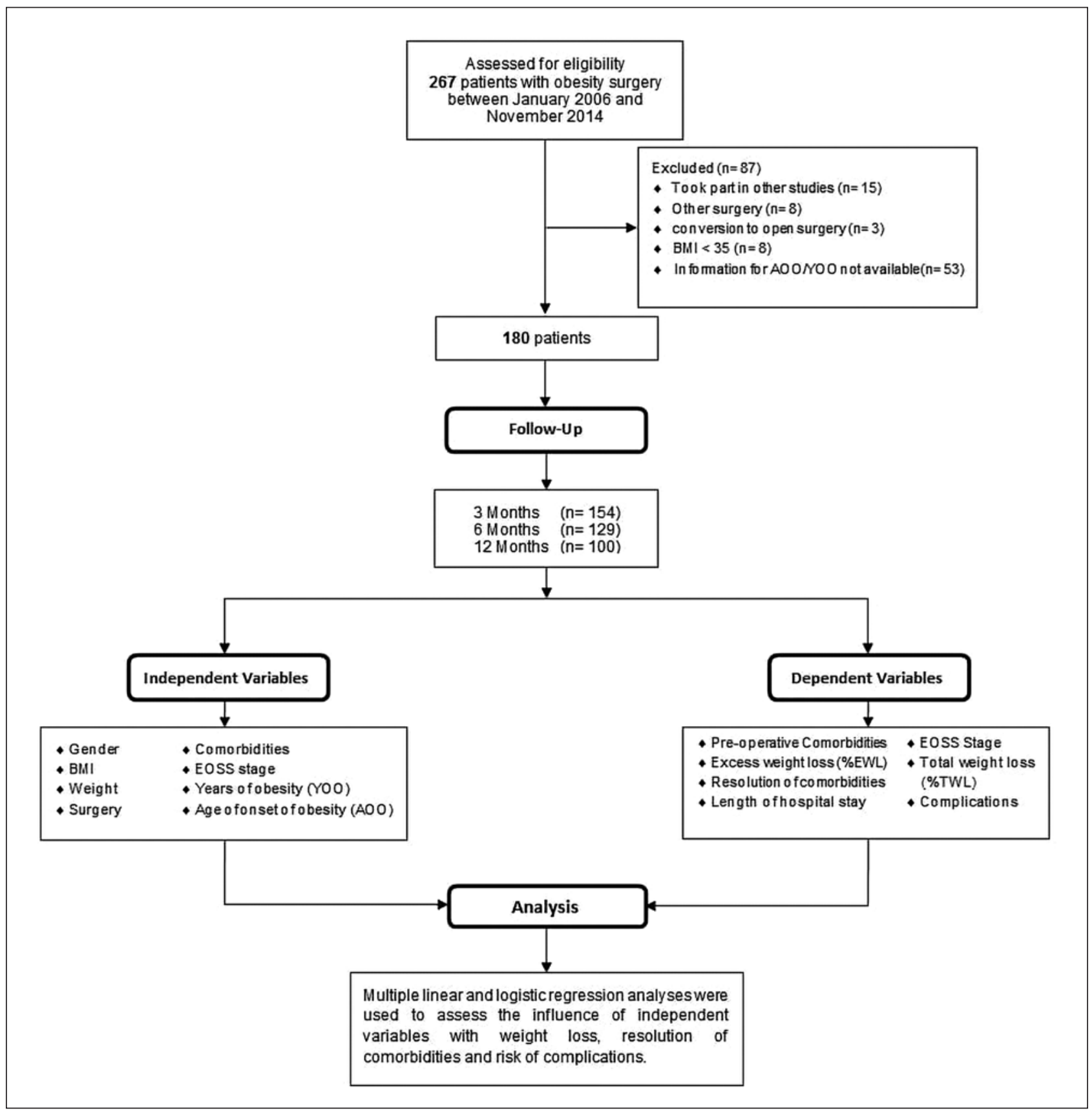

Fig. 1. Study flow chart. BMI, body mass index; EOSS, Edmonton obesity staging system.

2014, with indication for obesity surgery according to SAGES, ASMBS, IFSO, and the German S3 guidelines [20-22], and a BMI $\geq 40$ or 35-40 with major obesity-associated comorbidities. Selection between surgical procedures was conducted through shared decision-making. We excluded all patients who had surgeries other than RYGB or LSG, re-do surgery, or open surgery, or who were participating in concurring studies, and those with insufficient information on follow-up, AOO, and YOO. Patients with a BMI $<35$ were also excluded (Fig. 1).

Ethical approval was obtained from the local ethics committee at Heidelberg University (S-181/2009, S-618/2011, S-500/2012 and S-629/2013). Patients' gender, age, type of 
Nickel et al.: Predictors of Risk and Success of Obesity Surgery

Table 1. Demographic data and baseline characteristics of patients

\begin{tabular}{|c|c|c|c|}
\hline & RYGB $(n=48)$ & LSG $(n=132)$ & $p$ value \\
\hline \multicolumn{4}{|l|}{ Age at baseline, years } \\
\hline Mean \pm SD & $49.7 \pm 10.9$ & $45.8 \pm 11.0$ & 0.038 \\
\hline Range & 27-70 & 21-72 & \\
\hline \multicolumn{4}{|l|}{ Gender } \\
\hline Male & $15(31.2)$ & $50(37.8)$ & 0.520 \\
\hline Female & 33 (68.7) & $82(62.1)$ & \\
\hline \multicolumn{4}{|l|}{ Preoperative BMI } \\
\hline Mean \pm SD & $47.1 \pm 7.4$ & $50.4 \pm 7.3$ & 0.012 \\
\hline Range & $36.1-73.1$ & $36.6-74.0$ & \\
\hline \multicolumn{4}{|l|}{ Comorbidities } \\
\hline DM2 & $29(60.4)$ & $69(52.2)$ & 0.423 \\
\hline Arterial hypertension & $33(68.7)$ & $91(68.9)$ & 1 \\
\hline Joint pain & $23(47.9)$ & 77 (58.3) & 0.283 \\
\hline Reflux & $16(33.3)$ & 18 (13.6) & 0.005 \\
\hline Sleep apnea & $13(27.0)$ & $48(36.6)$ & 0.325 \\
\hline $\mathrm{AOO}$ & & & 0.011 \\
\hline Child & $10(20.8)$ & $60(45.4)$ & \\
\hline Adolescent & $12(25.0)$ & $20(15.1)$ & \\
\hline Adult & $20(41.6)$ & $39(29.5)$ & \\
\hline No information & $6(12.5)$ & $13(9.8)$ & \\
\hline \multicolumn{4}{|l|}{ YOO } \\
\hline Mean \pm SD & $27.0 \pm 11.3$ & $26.2 \pm 11.4$ & 0.698 \\
\hline Range & 8-56 & 5-51 & \\
\hline
\end{tabular}

Values express $n(\%)$, unless otherwise indicated. BMI, body mass index; DM2, diabetes mellitus type 2; A00, age of onset of obesity; YOO, years of obesity; RYGB, Roux-en-Y gastric bypass; LSG, laparoscopic sleeve gastrectomy.

surgery, preoperative weight and BMI, comorbidities, EOSS, YOO, and AOO were recorded. For AOO, we used 3 different classifications: childhood AOO (6-11 years), AOO as an adolescent (12-18 years), and adult AOO (>18 years). To determine patients' YOO, we calculated their current age minus A00. The influence of these parameters on \%EWL (initial weight minus actual weight, divided by initial weight minus ideal weight $\times 100$ ) and $\%$ total weight loss (\%TWL; operative weight minus follow-up weight, divided by operative weight $\times 100$ ) at 3 , 6 , and 12 months after surgery, preoperative comorbidities, the resolution of comorbidities, the risk of complications, and the length of hospitalization were investigated. The results were divided into preoperative and postoperative groups.

\section{Statistical Analysis}

Quantitative data were presented as mean \pm standard deviation for selected variables. Categorical variables were expressed as absolute and relative frequencies. Multiple linear and logistic regression analyses were used to assess the influence of several independent variables. The single coefficients $(\beta)$ in the linear regression model were used to describe the effects of the respective independent variables on the dependent variable adjusted for all other variables in the model. Single coefficients were represented as slopes in the regression models comparing independent variables; the higher the single coefficient, the higher the association. A negative $\beta$ implied that the corresponding independent variable was negatively 
Table 2. Logistic regression analysis of DM2 and predictor variables before obesity surgery
Table 3. Logistic regression analysis between preoperative arterial hypertension and predictor variables
Nickel et al.: Predictors of Risk and Success of Obesity Surgery

\begin{tabular}{lrlll}
\hline & Estimate, $\beta$ & SE & OR & $p$ \\
\hline Intercept & -0.189 & 0.324 & 0.828 & 0.562 \\
Age & 0.019 & 0.007 & 1.019 & 0.004 \\
\multicolumn{2}{l}{ Sex (reference: male) } & & & \\
$\quad$ Female & -0.026 & 0.080 & 0.974 & 0.741 \\
BMI & 0.002 & 0.005 & 1.002 & 0.717 \\
AOO (reference: childhood) & & & \\
$\quad$ Adolescence & -0.058 & 0.118 & 0.943 & 0.621 \\
$\quad$ Adulthood & -0.017 & 0.159 & 0.983 & 0.915 \\
YOO & -0.008 & 0.007 & 0.992 & 0.251 \\
\hline
\end{tabular}

$\beta$ describes the effects of the respective independent variables on the dependent variable. SE, standard error; OR, odds ratio; BMI, body mass index; DM2, diabetes mellitus type 2; AOO, age of onset of obesity; YOO, years of obesity.

\begin{tabular}{lclll}
\hline & Estimate, $\beta$ & SE & OR & $p$ \\
\hline Intercept & 0.101 & 0.306 & 1.106 & 0.742 \\
Age & 0.016 & 0.006 & 1.017 & 0.009 \\
\multicolumn{2}{l}{ Sex (reference: male) } & & & \\
$\quad$ Female & -0.051 & 0.075 & 0.950 & 0.495 \\
BMI & 0.002 & 0.005 & 1.002 & 0.723 \\
AOO (reference: childhood) & & & \\
$\quad$ Adolescence & -0.068 & 0.111 & 0.934 & 0.540 \\
$\quad$ Adulthood & -0.132 & 0.150 & 0.876 & 0.379 \\
YOO & -0.006 & 0.007 & 0.994 & 0.360 \\
\hline
\end{tabular}

$\beta$ describes the effects of the respective independent variables on the dependent variable. SE, standard error; OR, odds ratio; BMI, body mass index; AOO, age of onset of obesity; YOO, years of obesity.

associated with the dependent variable, and a positive $\beta$ implied a positive association. $p<$ 0.05 was considered statistically significant. Due to the exploratory nature of the study, no adjustment for multiplicity was performed.

\section{Results}

Out of 267 patients available during the study period, 180 fulfilled the inclusion criteria. There were $65(36.1 \%)$ male and $115(63.9 \%)$ female patients with a mean age of $46.8 \pm 11.1$ years, a preoperative weight of $145.5 \pm 26.8 \mathrm{~kg}$, and a preoperative BMI of $49.5 \pm 7.5$ (Table 1 ). Data on AOO was available for 161 patients and on YOO for 160 patients out of these 180 . $85.5 \%$ of patients were available at the 3 -month postoperative follow-up. For the 6- and 12-month follow-up, 71.6 and $55.5 \%$ of patients were available, respectively. There were 87 patients that matched the exclusion criteria. Fifteen patients were taking part in a concurring study, 8 had a surgery other than RYGB and LSG, and 3 had a conversion to open surgery. There were 8 patients with a preoperative BMI $\leq 35$ and 53 with insufficient information regarding follow-up, AOO, and YOO. 
Nickel et al.: Predictors of Risk and Success of Obesity Surgery

Table 4. Logistic regression analysis between sleep apnea and predictor variables before obesity surgery
Table 5. Logistic regression analysis between preoperative reflux and predictor variables

\begin{tabular}{lllll}
\hline & Estimate, $\beta$ & SE & OR & $p$ \\
\hline Intercept & -0.005 & 0.317 & 0.995 & 0.987 \\
Age & 0.011 & 0.006 & 1.011 & 0.093 \\
\multicolumn{2}{l}{ Sex (reference: male) } & & & \\
$\quad$ Female & -0.265 & 0.078 & 0.767 & 0.001 \\
BMI & 0.004 & 0.005 & 1.005 & 0.385 \\
AOO (reference: childhood) & & & \\
$\quad$ Adolescence & -0.131 & 0.115 & 0.878 & 0.258 \\
$\quad$ Adulthood & -0.110 & 0.155 & 0.896 & 0.480 \\
YOO & -0.005 & 0.007 & 0.995 & 0.446 \\
\hline
\end{tabular}

$\beta$ describes the effects of the respective independent variables on the dependent variable. SE, standard error; OR, odds ratio; BMI, body mass index; AOO, age of onset of obesity; YOO, years of obesity.

\begin{tabular}{|c|c|c|c|c|}
\hline & Estimate, $\beta$ & SE & $\mathrm{OR}$ & $p$ \\
\hline Intercept & 0.641 & 0.264 & 1.898 & 0.016 \\
\hline Age & 0.002 & 0.005 & 1.002 & 0.692 \\
\hline \multicolumn{5}{|c|}{ Sex (reference: male) } \\
\hline Female & 0.051 & 0.065 & 1.052 & 0.436 \\
\hline BMI & -0.009 & 0.004 & 0.991 & 0.037 \\
\hline \multicolumn{5}{|c|}{ AOO (reference: childhood) } \\
\hline Adolescence & -0.098 & 0.096 & 0.906 & 0.306 \\
\hline Adulthood & -0.098 & 0.129 & 0.907 & 0.451 \\
\hline YOO & -0.003 & 0.006 & 0.997 & 0.554 \\
\hline
\end{tabular}

$\beta$ describes the effects of the respective independent variables on the dependent variable. SE, standard error; OR, odds ratio; BMI, body mass index; AOO, age of onset of obesity; YOO, years of obesity.

\section{Preoperative Results}

Patients had a mean $3.5 \pm 1.7$ comorbidities. Linear regression showed that older age $(\beta=0.054, p=0.023)$ and greater BMI $(\beta=0.04, p=0.036)$ were the only predictors associated with a higher number of preoperative comorbidities. This means that patients had 1 more comorbidity with every 18.5 years of age and with every 25 BMI points.

Logistic regression analysis of the 5 most common comorbidities showed possible predictors for comorbidity. For DM2 (Table 2) and arterial hypertension (Table 3), the only significant predictor was older age. With every 10 years of age, a patient's risk of developing DM2 grew by $21 \%$ (odds ratio [OR] 1.019), and for hypertension the risk grew by $10 \%$ (OR .017). For sleep apnea, the covariate sex was predictive, with female patients at a lower risk (OR 0.767) (Table 4). Patients with greater BMI were less likely to have reflux than those with a low BMI (Table 5). AOO and YOO were not predictive of these comorbidities. No variable showed any influence on joint pain preoperatively. In the logistic regression analysis, patients who had AOO as an adult were $25.5 \%$ less likely to have an EOSS score $\geq 2$ than those with childhood AOO (OR 0.745, $p=0.043$ ). Patients who were 1 year older (OR 1.022, $p<0.001$ ) were $2 \%$ more likely to have an EOSS score $\geq 2$. This means that every 10 years the risk of having an EOSS score of at least 2 grew by $25 \%$. 
Nickel et al.: Predictors of Risk and Success of Obesity Surgery

Table 6. Linear regression analysis investigating the association of \%EWL 12 months after obesity surgery and predictor variables
Table 7. Logistic regression analysis between DM2 resolution 12 months after obesity surgery and predictor variables

\begin{tabular}{lrrr}
\hline & Estimate, $\beta$ & \multicolumn{1}{l}{ SE } & \multicolumn{1}{l}{$p$} \\
\hline Intercept & 137.972 & 14.949 & $<0.001$ \\
Age & -0.799 & 0.284 & 0.006 \\
Sex (reference: male) & & & \\
$\quad$ Female & 4.188 & 3.480 & 0.232 \\
RYGB (reference: LSG) & 4.950 & 3.989 & 0.218 \\
BMI & -1.236 & 0.235 & $<0.001$ \\
AOO (reference: childhood) & & & \\
$\quad$ Adolescence & 9.755 & 5.312 & 0.070 \\
$\quad$ Adulthood & 13.113 & 7.095 & 0.068 \\
YOO & 0.555 & 0.294 & 0.063 \\
\hline
\end{tabular}

$\beta$ describes the effects of the respective independent variables on the dependent variable. SE, standard error; \%EWL, percentage excess weight loss; BMI, body mass index; AOO, age of onset of obesity; YOO, years of obesity; RYGB, Roux-en-Y gastric bypass; LSG, laparoscopic sleeve gastrectomy.

\begin{tabular}{lclll}
\hline & Estimate, $\beta$ & SE & OR & $p$ \\
\hline Intercept & 0.483 & 0.516 & 1.622 & 0.352 \\
Age & -0.005 & 0.010 & 0.995 & 0.619 \\
Sex (reference: male) & & & & \\
$\quad$ Female & 0.237 & 0.122 & 1.267 & 0.057 \\
BMI & 0.001 & 0.008 & 1.001 & 0.855 \\
AOO (reference: childhood) & 0.009 & 0.180 & 1.009 & 0.960 \\
$\quad$ Adolescence & 0.030 & 0.236 & 1.031 & 0.899 \\
$\quad$ Adulthood & 0.007 & 0.010 & 1.007 & 0.499 \\
YOO & & & &
\end{tabular}

$\beta$ describes the effects of the respective independent variables on the dependent variable. SE, standard error; OR, odds ratio; DM2, diabetes mellitus type 2; BMI, body mass index; AOO, age of onset of obesity; YOO, years of obesity.

\section{Postoperative Results}

In the linear regression analysis, preoperative BMI had an impact on \%EWL at 3, 6, and 12 months, but no impact on \%TWL. Age was related to \%EWL and \%TWL at 12 months, with older patients showing a lower \%EWL $(\beta=-0.799, p=0.006)$ (Table 6) and \%TWL $(\beta=$ $-0.344, p=0.020$ ). \%TWL at 3 and 6 months after surgery had no statistically significant relation with any predictor.

Regarding possible predictors of resolution of comorbidities 12 months after surgery, the odds of having a DM2 resolution were $26 \%$ more likely for females (OR 1.267, $p=0.057$ ) (Table 7). Patients with adolescent AOO were 31\% less likely to have joint pain resolution than patients with AOO in childhood (OR 0.697, $p=0.019$ ) (Table 8).

Multiple logistic regression showed that BMI (OR 1.01, $p=0.020$ ) and EOSS (OR 1.147, $p=0.042$ ) were significant predictors of the risk of postoperative complications. Patients with an EOSS score $>1$ were $14 \%$ more likely to have postoperative complications (Table 9). With every $10 \mathrm{BMI}$ points, the risk of postoperative complications grew by $10.5 \%$. The median length of hospital stay after obesity surgery was 6 days. Patients who underwent RYGB had 
Nickel et al.: Predictors of Risk and Success of Obesity Surgery

Table 8. Logistic regression analysis between resolution of joint pain 12 months after obesity surgery and predictor variables
Table 9. Logistic regression analysis investigating the association of risk of complications and predictor variables after obesity surgery

\begin{tabular}{|c|c|c|c|c|}
\hline & Estimate, $\beta$ & SE & OR & $p$ \\
\hline Intercept & 0.602 & 0.426 & 1.825 & 0.162 \\
\hline Age & 0.004 & 0.008 & 1.004 & 0.630 \\
\hline \multicolumn{5}{|c|}{ Sex (reference: male) } \\
\hline Female & -0.091 & 0.109 & 0.913 & 0.406 \\
\hline BMI & 0.009 & 0.007 & 1.009 & 0.210 \\
\hline \multicolumn{5}{|c|}{ AOO (reference: childhood) } \\
\hline Adolescence & -0.362 & 0.151 & 0.697 & 0.019 \\
\hline Adulthood & -0.281 & 0.196 & 0.755 & 0.156 \\
\hline YOO & -0.011 & 0.009 & 0.989 & 0.242 \\
\hline
\end{tabular}

$\beta$ describes the effects of the respective independent variables on the dependent variable. BMI, body mass index; AOO, age of onset of obesity; YOO, years of obesity.

\begin{tabular}{lclll}
\hline & Estimate, $\beta$ & SE & OR & $p$ \\
\hline $\begin{array}{l}\text { Intercept } \\
\text { Number of preoperative }\end{array}$ & -0.537 & 0.257 & 0.585 & 0.038 \\
comorbidities & -0.008 & 0.021 & 0.992 & 0.703 \\
RYGB (reference: LSG) & 0.082 & 0.068 & 1.085 & 0.229 \\
AOO (reference: childhood) & & & & \\
$\quad$ Adolescence & 0.032 & 0.090 & 1.033 & 0.722 \\
$\quad$ Adulthood & 0.029 & 0.121 & 1.029 & 0.813 \\
EOSS score & 0.137 & 0.067 & 1.147 & 0.042 \\
Age & 0.001 & 0.005 & 1.001 & 0.890 \\
Sex (reference: male) & & & & \\
$\quad$ Female & 0.054 & 0.060 & 1.055 & 0.369 \\
BMI & 0.010 & 0.004 & 1.010 & 0.020 \\
YOO & -0.004 & 0.005 & 0.996 & 0.465 \\
\hline
\end{tabular}

$\beta$ describes the effects of the respective independent variables on the dependent variable. SE, standard error; OR, odds ratio; RYGB, Roux-en-Y gastric bypass; LSG, laparoscopic sleeve gastrectomy; BMI, body mass index; AOO age of onset of obesity; YOO, years of obesity; EOSS, Edmonton obesity staging system.

$66 \%$ lower odds of staying at least 7 days after surgery than those who underwent LSG (OR $0.660, p<0.001$ ). Patients with a higher EOSS score (OR 1.175, $p=0.022$ ) had an $18 \%$ higher risk of a longer hospital stay, while older patients (OR 1.016, $p=0.019$ ) had a greater probability of a longer hospital stay by $2 \%$ when age increased by 1 year.

\section{Discussion}

Age and BMI were found to be major predictors of \%EWL 12 months after obesity surgery. Patients with older age and greater BMI had a higher number of preoperative comorbidities and a higher risk of having an EOSS score $\geq 2$. A greater BMI and higher EOSS score were positive predictors of postoperative complications. High BMI patients had a lower \%EWL at 3,6 , and 12 months after obesity surgery. Older patients had a lower \%TWL than younger 
patients 12 months after surgery. Patients with AOO before adulthood were more likely to have an EOSS score $\geq 2$ and patients with AOO in adolescence were less likely to have joint pain resolution. YOO had no influence on patients' outcomes after obesity surgery.

Older age and greater BMI were also major predictors of preoperative comorbidities and $\%$ EWL at 3, 6, and 12 months after surgery. Age was a predictor of \%TWL at 12 months after surgery. Other studies also found that patients with BMI $>50$ had greater weight loss $[23,24]$. Although a high BMI normally correlates with higher \%EWL reduction, some studies have found older age and greater BMI to be negative predictors of \%EWL [25-28]. Findings on the influence of gender on weight loss are controversial. Some studies have found greater weight loss in women [26-28], others in men [29], and others found no gender differences [24, 25]. This study indicated that women had lower weight loss than men during the first 6 months after surgery. Patients with a low BMI had more reflux than those with a greater BMI. A study by Lagergren et al. [30] showed that those with overweight or obesity had an adjusted OR of 0.99 for reflux and they found no association between obesity and reflux. In contrast, other studies found reflux to be persistent in patients with a BMI $>35$, concluding that overweight and obesity are directly associated to the risk of reflux [31, 32].

There is limited evidence on the influence of the onset and/or duration of obesity [3335]. Some studies have found that an early onset and long duration of obesity attribute to a higher risk of obesity-related diseases. Stenholm et al. [33] reported an increased risk of walking limitation associated with an increased duration of self-reported recalled obesity after adjusting for education, smoking, alcohol, and chronic diseases. Sakurai et al. [35] found the duration of obesity, either ordinary or extreme, was associated with a significantly higher risk of non-insulin-dependent diabetes mellitus compared with no obesity, independent of other factors. In our study, there was no influence of AOO or YOO on the success and risks of obesity surgery. This means that obesity surgery can be successfully performed independently of the duration or onset of obesity.

Recent evidence suggests that obesity-related comorbidities, such as DM2, may be reversible with an EOSS score $\leq 2$. The EOSS may be an important tool to redefine indications for obesity surgery [36]. Stroud et al. [37] concluded that, while not every adolescent will benefit from obesity surgery, their model indicates that RYGB performed in adolescence improves quality-adjusted life expectancy compared with delayed surgery. As our patients with an earlier onset of obesity had a higher EOSS score, adequate treatment in the form of obesity surgery was not to be delayed. Outcome variables such as quality of life and comorbidities are encompassed in the EOSS tool and provide an overview of pre- and postoperative condition. A correlation between early onset of obesity and high EOSS score was found in this study. Due to its importance as a tool, EOSS should be taken into account, not only in the selection of patients and operative planning for bariatric surgery but also when analyzing the efficacy of the surgery.

As other publications state, RYGB and LSG are safe and effective surgeries for the treatment of obesity [38-41]. In our study, RYGB and LSG were both found to be safe and effective, with a notable \%EWL 12 months postoperatively (\%EWL: 69.5 for RYGB and 62 for LSG) and resolution of comorbidities. Patients who underwent RYGB had a higher mean \%EWL 12 months after surgery than those who underwent LSG. However, this is limited evidence as this was not a randomized trial. Results available in the literature show a wide range of \%EWL 12 months after surgery, i.e., 45-86\%, according to different study designs and inclusion criteria [38-41]. Multicenter randomized trials such as the ongoing BariSurg trial will result in better evidence for the comparison of LSG and RYGB [42].

Sugerman et al. [43] reported that hypertension and DM2 are associated with age in severely obese patients, stating that RYGB is an effective surgery for DM2 and hypertension resolution. The patients in their study that had an adequate \%EWL were more likely to have 
remission of obesity-related comorbidities. Iacobellis et al. [44] found no significant gender differences but concluded that age is the most significant preoperative predictor of DM2 remission. Hamza et al. [45] found \%EWL and younger age to be predictors of DM2 resolution after bariatric surgery. They stated that each additional 12 years of age lower the probability of DM2 remission by $20 \%$ after RYGB. We found a better DM2 resolution 12 months after surgery in women than in men, but age was not a significant preoperative predictor of DM2 resolution. Benaiges et al. [46] and Flores et al. [47] agreed that the only independent predictor of hypertension resolution after obesity surgery is the number of antihypertensive drugs used preoperatively. In our study, there was no significant influence of any variable for the resolution of hypertension. We showed that there was a significant reduction of joint pain 12 months after obesity surgery, mainly in patients with AOO as an adolescent. In other studies [48], 12 months after obesity surgery, joint pain was resolved in $>65 \%$ of patients, no matter which surgery was performed, although the duration and onset of obesity were not evaluated. Vincent et al. [49] concluded that obesity procedures show a promising relief of joint pain.

Numerous studies have shown that complications in obesity surgery are associated with a variety of factors: older age [50-54], surgical-team experience [55-57], greater BMI [54-58] and body weight [57], insufficient preoperative weight loss [59,60], and obesity-related comorbidities $[52,54,55]$. Chiappetta et al. [61] prospectively analyzed patients' preoperative EOSS score to predict if EOSS is useful for obesity surgery outcomes and concluded that patients with a score $\geq 3$ have a higher risk of postoperative complications. In our series, only 2 factors were independent predictors of complications after surgery. Patients with a greater BMI and a higher EOSS score had a higher risk of complications. Older age was not independently associated with the risk of complications. With a median hospital stay of 6 days, RYGB patients had a shorter stay than patients with LSG. However, it must be stated this could have been an effect caused by the learning curve of the surgical team in the early LSGs performed, and involved complications associated with a prolonged hospital stay and involved a more cautious discharge policy [62].

In conclusion, our study demonstrated the importance of BMI and age as predictors of weight loss after obesity surgery. Furthermore, a higher EOSS score and greater BMI were predictive of a risk of complications. Success and risks of obesity surgery were independent of the duration of obesity and AOO, but AOO in adolescence had an influence on joint pain resolution and an EOSS score $\geq 2$ had an association with the risk of complications. Therefore, obesity surgery should be performed as early as possible, to avoid the risk of unnecessary complications which increases along with higher EOSS score and greater BMI. Earlier surgery also provides the best option for weight loss and the resolution of comorbidities.

\section{Acknowledgement}

We would like to thank Sarah Trent for proofreading the manuscript.

\section{Statement of Ethics}

Ethical approval was obtained from the local ethics committee at Heidelberg University (S-181/2009, S-618/2011, S-500/2012 and S-629/2013).

\section{Disclosure Statement}

The authors have no conflicts of interest to declare. 
Nickel et al.: Predictors of Risk and Success of Obesity Surgery

\section{Funding Sources}

We acknowledge financial support from the Deutsche Forschungsgemeinschaft within the funding program for open-access publishing, the Baden-Württemberg Ministry of Science, Research and the Arts, and the Ruprecht-Karls-Universität Heidelberg.

\section{Author Contributions}

All of the authors contributed according to the ICMJE criteria for authorship, i.e., substantial contributions to the conception, acquisition, analysis, and interpretation of data; drafting the work and revising it critically for important intellectual content; final approval of the version to be published; and agreement to be accountable for all aspects of the work in ensuring that questions related to the accuracy or integrity of any part of the work are appropriately investigated and resolved.

\section{References}

1 James PT. Obesity: the worldwide epidemic. Clin Dermatol. 2004 Jul-Aug;22(4):276-80.

2 Guh DP, Zhang W, Bansback N, Amarsi Z, Birmingham CL, Anis AH. The incidence of co-morbidities related to obesity and overweight: a systematic review and meta-analysis. BMC Public Health. 2009 Mar;9(1):88.

3 Pi-Sunyer X. The medical risks of obesity. Postgrad Med. 2009 Nov;121(6):21-33.

4 Ogden CL, Carroll MD, Kit BK, Flegal KM. Prevalence of obesity and trends in body mass index among US children and adolescents, 1999-2010. JAMA. 2012 Feb;307(5):483-90.

5 Freedman DS, Mei Z, Srinivasan SR, Berenson GS, Dietz WH. Cardiovascular risk factors and excess adiposity among overweight children and adolescents: the Bogalusa Heart Study. J Pediatr. 2007 Jan;150(1):12-17.e2.

6 Singh AS, Mulder C, Twisk JW, van Mechelen W, Chinapaw MJ. Tracking of child hood overweight into adulthood: a systematic review of the literature. Obes Rev. 2008 Sep;9(5):474-88.

7 Alberga AS, Sigal RJ, Goldfield G, Prud'homme D, Kenny GP. Overweight and obese teenagers: why is adolescence a critical period? Pediatr Obes. 2012 Aug;7(4):261-73.

8 Sjöström L, Lindroos AK, Peltonen M, Torgerson J, Bouchard C, Carlsson B, et al; Swedish Obese Subjects Study Scientific Group. Lifestyle, diabetes, and cardiovascular risk factors 10 years after bariatric surgery. N Engl J Med. 2004 Dec;351(26):2683-93.

9 Nickel F, Schmidt L, Bruckner T, Billeter AT, Kenngott HG, Müller-Stich BP, et al. Gastrointestinal Quality of Life Improves Significantly after Sleeve Gastrectomy and Roux-en-Y Gastric Bypass - A Prospective Cross-Sectional Study within a 2-Year Follow-up. Obes Surg. 2017 May;27(5):1292-7.

10 Nickel F, Schmidt L, Bruckner T, Büchler MW, Müller-Stich BP, Fischer L. Influence of bariatric surgery on quality of life, body image, and general self-efficacy within 6 and 24 months-a prospective cohort study. Surg Obes Relat Dis. 2017 Feb;13(2):313-9.

11 Billeter AT, Senft J, Gotthardt D, Knefeli P, Nickel F, Schulte T, et al. Combined Non-Alcoholic Fatty Liver Disease and Type 2 Diabetes Mellitus: Sleeve Gastrectomy or Gastric Bypass? A Controlled Matched Pair Study of 34 Patients. Obes Surg. 2016 Aug;26(8):1867-74.

12 Müller-Stich BP, Fischer L, Kenngott HG, Gondan M, SenftJ, Clemens G, etal. Gastric bypass leads to improvement of diabetic neuropathy independent of glucose normalization -results of a prospective cohort study (DiaSurg 1 study). Ann Surg. 2013 Nov;258(5):760-5.

13 El Chaar M, Hammoud N, Ezeji G, Claros L, Miletics M, Stoltzfus J. Laparoscopic sleeve gastrectomy versus laparoscopic Roux-en-Y gastric bypass: a single center experience with 2 years follow-up. Obes Surg. 2015 Feb; 25(2):254-62.

14 Soto FC, Gari V, de la Garza JR, Szomstein S, Rosenthal RJ. Sleeve gastrectomy in the elderly: a safe and effective procedure with minimal morbidity and mortality. Obes Surg. 2013 Sep;23(9):1445-9.

15 Sharma AM, Kushner RF. A proposed clinical staging system for obesity. Int J Obes. 2009 Mar;33(3):289-95.

16 Maggard MA, Shugarman LR, Suttorp M, Maglione M, Sugerman HJ, Livingston EH, et al. Meta-analysis: surgical treatment of obesity. Ann Intern Med. 2005 Apr;142(7):547-59.

17 Kinzl JF, Schrattenecker M, Traweger C, Mattesich M, Fiala M, Biebl W. Psychosocial predictors of weight loss after bariatric surgery. Obes Surg. 2006 Dec;16(12):1609-14.

18 Fischer L, Nickel F, Sander J, Ernst A, Bruckner T, Herbig B, et al. Patient expectations of bariatric surgery are gender specific—a prospective, multicenter cohort study. Surg Obes Relat Dis. 2014 May-Jun;10(3):516-23.

19 Fischer L, Wekerle AL, Sander J, Nickel F, Billeter AT, Zech U, et al. Is there a Reason Why Obese Patients Choose Either Conservative Treatment or Surgery? Obes Surg. 2017 Jul;27(7):1684-90. 
20 SAGES Guidelines Committee. SAGES guideline for clinical application of laparoscopic bariatric surgery. Surg Obes Relat Dis. 2009 May-Jun;5(3):387-405.

21 Allied Health Sciences Section Ad Hoc Nutrition Committee; Aills L, Blankenship J, Buffington C, Furtado M, Parrott J. ASMBS Allied Health Nutritional Guidelines for the Surgical Weight Loss Patient. Surg Obes Relat Dis. 2008; 4:S73-108.

22 Fried M, Hainer V, Basdevant A, Buchwald H, Deitel M, Finer N, et al. Inter-disciplinary European guidelines on surgery of severe obesity. Int J Obes. 2007 Apr;31(4):569-77.

23 Menenakos E, Stamou KM, Albanopoulos K, Papailiou J, Theodorou D, Leandros E. Laparoscopic sleeve gastrectomy performed with intent to treat morbid obesity: a prospective single-center study of 261 patients with a median follow-up of 1 year. Obes Surg. 2010 Mar;20(3):276-82.

24 Lee YC, Lee WJ, Lee TS, Lin YC, Wang W, Liew PL, et al. Prediction of successful weight reduction after bariatric surgery by data mining technologies. Obes Surg. 2007 Sep;17(9):1235-41.

25 Ortega E, Morínigo R, Flores L, Moize V, Rios M, Lacy AM, et al. Predictive factors of excess body weight loss 1 year after laparoscopic bariatric surgery. Surg Endosc. 2012 Jun;26(6):1744-50.

26 Bueter M, Thalheimer A, Lager C, Schowalter M, Illert B, Fein M. Who benefits from gastric banding? Obes Surg. 2007 Dec;17(12):1608-13.

27 Chevallier JM, Paita M, Rodde-Dunet MH, Marty M, Nogues F, Slim K, et al. Predictive factors of outcome after gastric banding: a nationwide survey on the role of center activity and patients' behavior. Ann Surg. 2007 Dec; 246(6):1034-9.

28 Dallal RM, Quebbemann BB, Hunt LH, Braitman LE. Analysis of weight loss after bariatric surgery using mixedeffects linear modeling. Obes Surg. 2009 Jun;19(6):732-7.

29 Ma Y, Pagoto SL, Olendzki BC, Hafner AR, Perugini RA, Mason R, et al. Predictors of weight status following laparoscopic gastric bypass. Obes Surg. 2006 Sep;16(9):1227-31.

30 Lagergren J, Bergström R, Nyrén 0. No relation between body mass and gastro-oesophageal reflux symptoms in a Swedish population-based study. Gut. 2000 Jul;47(1):26-9.

31 Cremonini F, Locke GR 3rd, Schleck CD, Zinsmeister AR, Talley NJ. Relationship between upper gastrointestinal symptoms and changes in body weight in a population-based cohort. Neurogastroenterol Motil. 2006 Nov;18(11):987-94.

32 El-Serag HB, Graham DY, Satia JA, Rabeneck L. Obesity is an independent risk factor for GERD symptoms and erosive esophagitis. Am J Gastroenterol. 2005 Jun;100(6):1243-50.

33 Stenholm S, Rantanen T, Alanen E, Reunanen A, Sainio P, Koskinen S. Obesity history as a predictor of walking limitation at old age. Obesity (Silver Spring). 2007 Apr;15(4):929-38.

34 Wong E, Tanamas SK, Wolfe R, Backholer K, Stevenson C, Abdullah A, et al. The role of obesity duration on the association between obesity and risk of physical disability. Obesity (Silver Spring). 2015 Feb;23(2):443-7.

35 Sakurai Y, Teruya K, Shimada N, Umeda T, Tanaka H, Muto T, et al. Association between duration of obesity and risk of non-insulin-dependent diabetes mellitus. The Sotetsu Study. Am J Epidemiol. 1999 Feb;149(3):256-60.

36 Gill RS, Karmali S, Sharma AM. The potential role of the Edmonton obesity staging system in determining indications for bariatric surgery. Obes Surg. 2011 Dec;21(12):1947-9.

37 Stroud AM, Parker D, Croitoru DP. Timing of bariatric surgery for severely obese adolescents: a Markov decision-analysis. J Pediatr Surg. 2016 May;51(5):853-8.

38 Vidal P, Ramón JM, Goday A, Benaiges D, Trillo L, Parri A, et al. Laparoscopic gastric bypass versus laparoscopic sleeve gastrectomy as a definitive surgical procedure for morbid obesity. Mid-term results. Obes Surg. 2013 Mar;23(3):292-9.

39 LeybaJL, Aulestia SN, Llopis SN. Laparoscopic Roux-en-Y gastric bypass versus laparoscopic sleevegastrectomy for the treatment of morbid obesity. A prospective study of 117 patients. Obes Surg. 2011 Feb;21(2):212-6.

40 Wittgrove AC, Clark GW. Laparoscopic gastric bypass, Roux-en-Y 500 patients: technique and results, with 3-60-month follow-up. Obes Surg. 2000 Jun;10(3):233-9.

41 Cottam D, Qureshi FG, Mattar SG, Sharma S, Holover S, Bonanomi G, et al. Laparoscopic sleeve gastrectomy as an initial weight-loss procedure for high-risk patients with morbid obesity. Surg Endosc. 2006 Jun;20(6): 859-63.

42 Fischer L, Wekerle AL, Bruckner T, Wegener I, Diener MK, Frankenberg MV, et al. BariSurg trial: sleeve gastrectomy versus Roux-en-Y gastric bypass in obese patients with BMI 35-60 kg/m(2) - a multi-centre randomized patient and observer blind non-inferiority trial. BMC Surg. 2015 Jul;15(1):87.

43 Sugerman HJ, Wolfe LG, Sica DA, Clore JN. Diabetes and hypertension in severe obesity and effects of gastric bypass-induced weight loss. Ann Surg. 2003 Jun;237(6):751-6.

44 Iacobellis G, Xu C, Campo RE, De La Cruz-Munoz NF. Predictors of short-term diabetes remission after laparoscopic Roux-en-Y gastric bypass. Obes Surg. 2015 May;25(5):782-7.

45 Hamza N, Abbas MH, Darwish A, Shafeek Z, New J, Ammori BJ. Predictors of remission of type 2 diabetes mellitus after laparoscopic gastric banding and bypass. Surg Obes Relat Dis. 2011 Nov-Dec;7(6):691-6.

46 Benaiges D, Sagué M, Flores-Le Roux JA, Pedro-Botet J, Ramón JM, Villatoro M, et al. Predictors of Hypertension Remission and Recurrence after Bariatric Surgery. Am J Hypertens. 2016 May;29(5):653-9.

47 Flores L, Vidal J, Canivell S, Delgado S, Lacy A, Esmatjes E. Hypertension remission 1 year after bariatric surgery: predictive factors. Surg Obes Relat Dis. 2014 Jul-Aug;10(4):661-5.

48 Zhang N, Maffei A, Cerabona T, Pahuja A, Omana J, Kaul A. Reduction in obesity-related comorbidities: is gastric bypass better than sleeve gastrectomy? Surg Endosc. 2013 Apr;27(4):1273-80. 
Nickel et al.: Predictors of Risk and Success of Obesity Surgery

49 Vincent HK, Ben-David K, Cendan J, Vincent KR, Lamb KM, Stevenson A. Effects of bariatric surgery on joint pain: a review of emerging evidence. Surg Obes Relat Dis. 2010 Jul-Aug;6(4):451-60.

50 O’Rourke RW, Andrus J, Diggs BS, Scholz M, McConnell DB, Deveney CW. Perioperative morbidity associated with bariatric surgery: an academic center experience. Arch Surg. 2006 Mar;141(3):262-8.

51 Livingston EH, Huerta S, Arthur D, Lee S, De Shields S, Heber D. Male gender is a predictor of morbidity and age a predictor of mortality for patients undergoing gastric bypass surgery. Ann Surg. 2002 Nov;236(5):57682.

52 Maciejewski ML, Winegar DA, Farley JF, Wolfe BM, DeMaria EJ. Risk stratification of serious adverse events after gastric bypass in the Bariatric Outcomes Longitudinal Database. Surg Obes Relat Dis. 2012 Nov-Dec;8(6): 671-7.

53 Bergeat D, Lechaux D, Ghaina A, Thibault R, Bouygues V. Postoperative Outcomes of Laparoscopic Bariatric Surgery in Older Obese Patients: a Matched Case-Control Study. Obes Surg. 2017 Jun;27(6):1414-22.

54 Al-Khyatt W, Ryall R, Leeder P, Ahmed J, Awad S. Predictors of Inadequate Weight Loss After Laparoscopic Gastric Bypass for Morbid Obesity. Obes Surg. 2017 Jun;27(6):1446-52.

55 Campos GM, Ciovica R, Rogers SJ, Posselt AM, Vittinghoff E, Takata M, et al. Spectrum and risk factors of complications after gastric bypass. Arch Surg. 2007;142:969-75.

56 Birkmeyer NJ, Dimick JB, Share D, Hawasli A, English WJ, Genaw J, et al.; Michigan Bariatric Surgery Collaborative. Hospital complication rates with bariatric surgery in Michigan. JAMA. 2010 Jul;304(4):435-42.

57 Suter M, Giusti V, Héraief E, Zysset F, Calmes JM. Laparoscopic Roux-en-Y gastric bypass: initial 2-year experience. Surg Endosc. 2003 Apr;17(4):603-9.

58 Sánchez-Santos R, Vilarrasa N, Pujol J, Moreno P, Manuel Francos J, Rafecas A, et al. Is Roux-en-Y gastric bypass adequate in the super-obese? Obes Surg. 2006 Apr;16(4):478-83.

59 Steinbeisser M, McCracken J, Kharbutli B. Laparoscopic Sleeve Gastrectomy: Preoperative Weight Loss and Other Factors as Predictors of Postoperative Success. Obes Surg. 2017 Jun;27(6):1508-13.

60 Ledoux S, Sami O, Breuil MC, Delapierre M, Calabrese D, Msika S, et al. Relevance of Self-reported Behavioral Changes before Bariatric Surgery to Predict Success after Surgery. Obes Surg. 2017 Jun;27(6):1453-9.

61 Chiappetta S, Stier C, Squillante S, Theodoridou S, Weiner RA. The importance of the Edmonton obesity staging system in predicting postoperative outcome and 30-day mortality after metabolic surgery. Surg Obes Relat Dis. 2016 Dec;12(10):1847-55.

62 Fischer L, El Zein Z, Bruckner T, Hünnemeyer K, Rudofsky G, Reichenberger M, et al. Herausforderungen beim Aufbau eines operativen Adipositaszentrums. Chirurg. 2014;85(4):334-41. 